\title{
Ocorrência e ecologia trófica de quatro espécies de Astyanax (Characidae) em diferentes rios da bacia do rio Tibagi, Paraná, Brasil
}

\author{
Sirlei Terezinha Bennemann, Ana Maria Gealh², Mário Luís Orsi ${ }^{1} \&$ Leda Maria de Souza ${ }^{2}$ \\ 1. Centro de Ciências Biológicas, Departamento de Biologia Animal e Vegetal, Universidade Estadual de Londrina, Campus Universitário, \\ Caixa Postal 6001, 86051-990 Londrina, Paraná, Brasil. (sirlei@uel.br) \\ 2. Departamento de Biologia Geral, Universidade Estadual de Ponta Grossa, Praça Santos Andrade, s/n., 84010-970 Ponta Grossa, \\ Paraná, Brasil.
}

\begin{abstract}
Occurrence and trophic ecology of four species of Astyanax (Characidae) in different rivers of the Tibagi River Basin, Paraná, Brazil. Stretches of the Rivers Fortaleza, Iapó and Tibagi were monthly sampled with gillnets of different mesh sizes and castnets from May 2001 to April 2002 in the Tibagi River basin. Specimens of four species of the Astyanax genera were captured. In order to assess how they use habitat and food resources in the different rivers, their constancy was calculated and the number of specimens was compared by using the Bray-Curtis similarity analysis. The composition (percentage) of food items consumed was ordered by using the Principal Components Analysis (PCA). The proportion of different food items in the diet was assessed and classified according to type (animal or plant material) and origin (allochtonous or autochtonous). The low similarity and constancy showed differences in the type of habitat preferred by the four fish species. Astyanax altiparanae Garutti \& Britski, 2000 and A. fasciatus (Cuvier, 1819) were present in the large rivers but were constant only in the Tibagi River. Astyanax eigenmanniorum (Cope, 1894) was present in all rivers but prefers habitats in the mouth of affluents of large rivers. Astyanax scabripinnis (Jenyns, 1842) was restricted to Fortaleza River, a small Tibagi River affluent. The number of food items consumed by the different species varied from 11 to 23. Among the main food, three items were common for the four species: 1- plant residuals (leaves and seeds from the earth community of plants), 2- insect residuals (from different origins and unidentified) and 3- aquatic vegetation. So plants and insects were the main food consumed by all the species. Astyanax eigenmanniorum showed the highest distinction in the diet composition among the species studied. Such distinction was due to its ability of exploring an abundant food resource: the aquatic plants that were consumed together with portions of coal/sediments near the rocky shores at the Iapó River. The similarity of the origin and type of food consumed by the four species and the differences in terms of the habitat occupied may explain why one species is abundant and constant in only one of the river stretches studied.
\end{abstract}

KEYWORDS. Astyanax, trophic ecology, Tibagi River Basin, rivers.

RESUMO. Na bacia do rio Tibagi, trechos dos rios Fortaleza, Iapó e Tibagi foram amostrados mensalmente, de maio de 2001 a abril de 2002, com tarrafas e redes de espera de diferentes malhagens. Foram capturados indivíduos de quatro espécies de Astyanax. Para conhecer como essas espécies utilizam o hábitat desses rios, foi calculada a constância, e as frequêencias em número de exemplares foram comparadas pela análise de similaridade Bray-Curtis. A composição percentual dos alimentos consumidos foi ordenada usandose a Análise de Componentes Principais (ACP). As proporções dos recursos alimentares foram avaliadas e classificadas quanto à natureza (animal ou material vegetal) e origem (alóctone e autóctone). A constância e a baixa similaridade na abundância revelaram que as espécies têm preferências quanto ao porte do rio ou por determinado hábitat. Astyanax altiparanae Garutti \& Britski, 2000 e A. fasciatus (Cuvier, 1819) ocorreram nos de maior porte, mas foram constantes somente no rio Tibagi. Astyanax eigenmanniorum (Cope, 1894) ocorreu em todos os rios, mas prefere hábitats próximos às desembocaduras de afluentes de grandes rios. Astyanax scabripinnis (Jenyns, 1842) esteve restrita ao Fortaleza, o rio de menor porte, subafluente do rio Tibagi. O número de itens alimentares consumidos variou de 11 a 23. Entre os alimentos principais, três itens foram comuns para as quatro espécies: restos de plantas (folhas e sementes de plantas terrestres), restos de insetos (de diferentes origens e não identificados) e plantas aquáticas. Os vegetais e os insetos foram os principais alimentos para todas as espécies. A maior distinção na composição da dieta foi constatada para A. eigenmaniorum, devido à sua habilidade em explorar as plantas aquáticas, presentes em abundância, consumidas junto com carvão/ sedimento, que estavam nas margens rochosas do rio Iapó. A similaridade quanto à origem e ao tipo de alimento consumido pelas quatro espécies e as diferenças em termos de hábitat ocupado podem explicar por que apenas uma delas se mantém em abundância e constância em cada trecho estudado.

PALAVRAS-CHAVE. Astyanax, ecologia trófica, bacia do rio Tibagi, rios.

Os peixes da bacia do rio Tibagi têm sido estudados, principalmente nas regiões média e inferior, quanto à diversidade e ecologia (BENNEMANN et al., 2000; Bennemann \& Shibatta, 2002; Shibatta et al., 2002), biologia (ORSI et al., 2002) e reprodução (VEREGUE \& ORSI, 2003). As regiões superior, média e inferior foram estudadas por BENNEMANN et al. (1995), que constataram, em cinco trechos amostrados, apenas duas espécies comuns a todos eles, entre 69 registradas. Uma delas foi Astyanax altiparanae Garutti \& Britski, 2000, anteriormente denominada de Astyanax bimaculatus.

Em afluentes e subafluentes (rios de pequena ordem) das regiões média e inferior da bacia do rio Tibagi,
SHiBATTA et al. (2002) assinalaram a presença de quatro espécies pertencentes ao gênero Astyanax: A. altiparanae, A. eigenmanniorum (Cope, 1894), A. fasciatus (Cuvier, 1819) e A. scabripinnis (Jenyns, 1842), as três primeiras amplamente distribuídas nos afluentes e subafluentes nas duas regiões e a última, presente somente nos subafluentes. Segundo os autores, a distribuição dessas espécies está relacionada ao porte do rio.

$\mathrm{Na}$ região superior da bacia foram realizados levantamentos em dois trechos do rio Tibagi, em um trecho de um afluente e em um de um subafluente, e essas quatro espécies foram registradas (A. M. Gealh, dados 
não publicados), seguindo o mesmo padrão encontrado por ShiBATTA et al. (2002).

Neste trabalho, com o objetivo de entender a maneira como as espécies A. altiparanae, $A$. eigenmanniorum, A. fasciatus e A. scabripinnis utilizam os recursos na bacia do rio Tibagi, foram avaliados, em trechos de rios de diferentes portes, os seguintes aspectos: constância nas capturas dessas espécies, composição e dominância dos recursos alimentares utilizados por elas e proporções do seu conteúdo estomacal quanto ao tipo (animal, vegetal e detrito/ sedimento) e à origem (alóctone e autóctone).

\section{MATERIAL E MÉTODOS}

Foram amostrados um trecho do rio Fortaleza, um do Iapó e dois do rio Tibagi, um deles cerca de $60 \mathrm{~km}$ acima do Salto Mauá e o outro cerca de $20 \mathrm{~km}$ abaixo, aqui denominados Tibagi acima e Tibagi abaixo (Fig. 1). Os dois primeiros rios se situam na região dos Campos Gerais.

O rio Fortaleza (Fig. 2a) é um afluente da margem direita do rio Iapó. Apresenta-se encaixado, tem muitos saltos, formando cachoeiras e áreas de corredeiras, e encontra-se em estado de franca erosão. O trecho de coleta está localizado na fazenda Santo Amaro, no município de Tibagi.

O rio Iapó (Fig. 2b) é um dos principais afluentes da margem direita do Tibagi. Apresenta-se encaixado em vale, com trechos de corredeiras entremeados por amplas várzeas pantanosas. Os locais de amostragem situam-se à jusante do canyon do Guartelá, na fazenda Capão Grande, também no município de Tibagi. O trecho amostrado situa-se próximo à desembocadura do rio Iapó.

O rio Tibagi é o principal afluente do rio Paranapanema, e origina-se na região dos Campos Gerais; percorre aproximadamente $550 \mathrm{~km}$ até sua foz (MAACK, 1968) e apresenta grande número de cachoeiras. Os trechos Tibagi acima e Tibagi abaixo têm como referência a cachoeira do Salto Mauá, que é aproveitada pela Usina Hidrelétrica Presidente Vargas, no município de Telêmaco Borba. $\mathrm{O}$ trecho amostrado à montante do Salto Mauá se localiza no município de Tibagi (Fig. 2c); o trecho amostrado à jusante se localiza na fazenda Recreio Bom Jesus, no município de Curiúva (Fig. 2d). Outras características dos rios e trechos amostrados estão mencionadas na tabela I.
As capturas foram realizadas mensalmente de maio de 2001 a abril de 2002. Para cada trecho de coleta, o esforço de pesca foi de $1.000 \mathrm{~m}^{2}$ de redes de espera simples, com malhas de 2 a $12 \mathrm{~cm}$ entre nós opostos, durante 24 horas, com despescas a cada 12 horas; de forma complementar, em todos os trechos foram feitas capturas com tarrafas de malha $4 \mathrm{~cm}$.

De cada exemplar, após a identificação específica, foram tomados dados do comprimento total $(\mathrm{Ct})$ e do comprimento padrão $(\mathrm{Cp})$ (em centímetros) e do peso total (Pt) (em gramas); os tratos digestórios foram retirados e fixados (formalina a $10 \%$ ), para posterior análise de conteúdo.

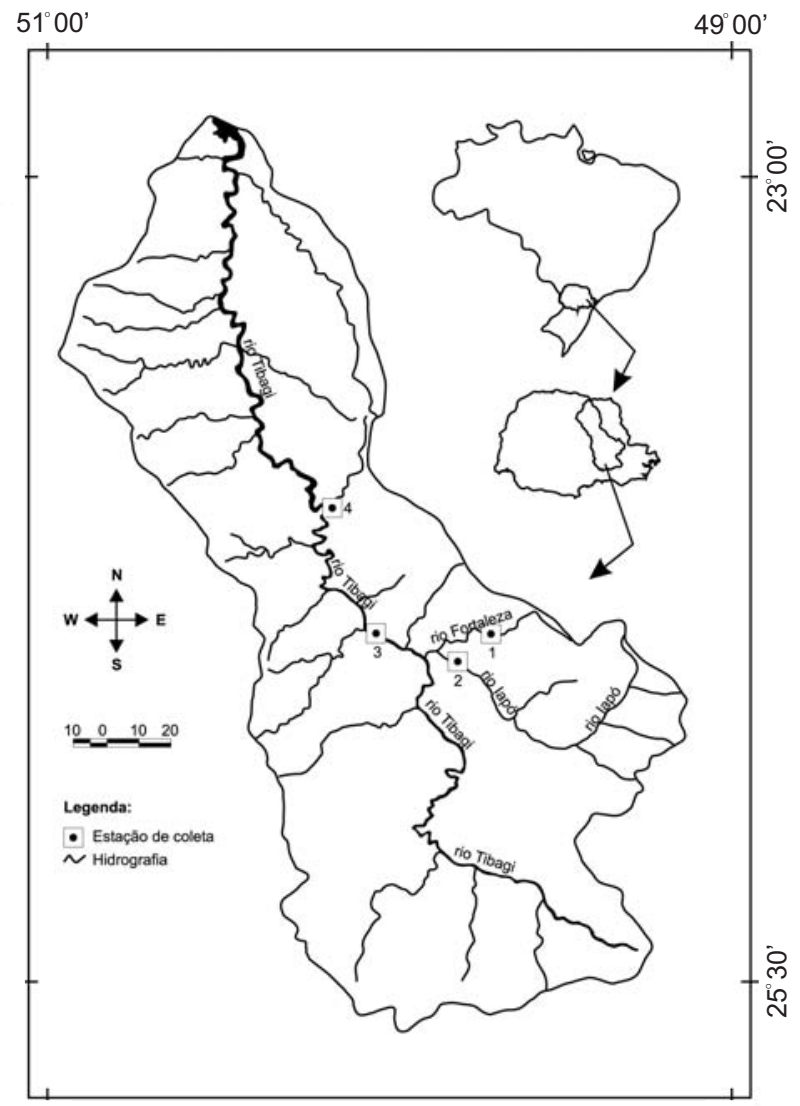

Fig. 1. Mapa da bacia hidrográfica do rio Tibagi com a localização dos rios e dos trechos amostrados.

Tabela I. Características ambientais dos trechos do rio Tibagi e dos afluentes amostrados no período de maio de 2001 a abril de 2002.

\begin{tabular}{|c|c|c|c|c|}
\hline \multirow[b]{2}{*}{ Características } & \multicolumn{4}{|c|}{ Trechos amostrados } \\
\hline & Fortaleza & Iapó & Tibagi acima & Tibagi abaixo \\
\hline Coordenadas & $50^{\circ} 20^{\prime} \mathrm{S} \quad 24^{\circ} 40^{\prime} \mathrm{W}$ & $50^{\circ} 0^{\prime} \mathrm{S} 24^{\circ} 51^{\prime} \mathrm{W}$ & $50^{\circ} 54^{\prime} \mathrm{S} \quad 24^{\circ} 42^{\prime} \mathrm{W}$ & $50^{\circ} 70^{\prime} \mathrm{S} \quad 24^{\circ} 02^{\prime} \mathrm{W}$ \\
\hline Extensão do rio $(\mathrm{km})$ & 71 & 130 & 550 & 550 \\
\hline Largura no local amostrado (m) & 20 & 60 & 130 & 150 \\
\hline Profundidade no local amostrado & Trechos rasos até $4 \mathrm{~m}$ & Trechos rasos até $6 \mathrm{~m}$ & Trechos rasos até $15 \mathrm{~m}$ & $\begin{array}{l}\text { Trechos rasos e poções } \\
\text { até } 50 \mathrm{~m}\end{array}$ \\
\hline Fluxo da água & Corredeiras & Poucas corredeiras & Poucas corredeiras & Corredeiras \\
\hline Substrato & $\begin{array}{l}\text { Rochoso, com areia } \\
\text { média e grossa }\end{array}$ & $\begin{array}{l}\text { Rochoso e } \\
\text { areno-argiloso }\end{array}$ & Rochoso e arenoso & Rochoso e arenoso \\
\hline Vegetação aquática & Poucas macrófitas & Macrófitas abundantes & $\begin{array}{l}\text { Macrófitas na margem } \\
\text { esquerda }\end{array}$ & Sem macrófitas \\
\hline Região do rio & Média & Foz & Média & Média \\
\hline Ordem do rio & $3^{\mathrm{a}}$ & $4^{\mathrm{a}}$ & $5^{\mathrm{a}}$ & $5^{\mathrm{a}}$ \\
\hline
\end{tabular}



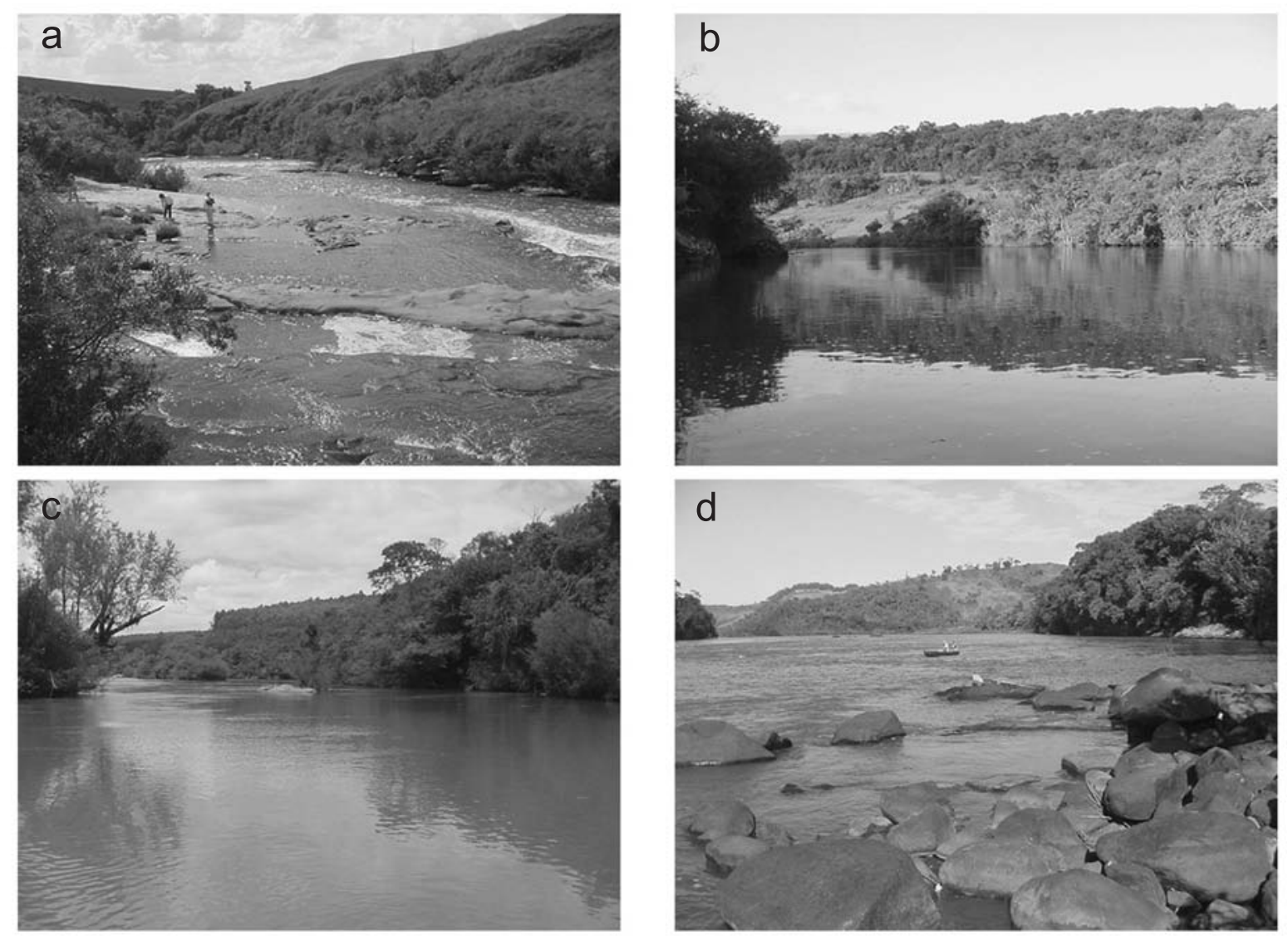

Fig. 2. Trechos amostrados no rio Tibagi e nos seus afluentes no período de maio de 2001 a abril de 2002 : a, rio Fortaleza; b, rio Iapó; c, rio Tibagi (à montante do Salto Mauá); d, rio Tibagi (à jusante do Salto Mauá).

Espécimes-testemunho (das espécies de Astyanax aqui analisadas e das demais espécies coletadas) de cada trecho estudado foram depositados no Museu de Zoologia da Universidade Estadual de Londrina (MZUEL, curador O. A. Shibatta).

As espécies consideradas constantes estiveram presentes em mais de $50 \%$ das coletas; as acessórias, entre $25 \%$ e $50 \%$, inclusive; as acidentais, em menos de $25 \%$ das coletas. Para comparação entre os pontos de coleta, foi efetuada a análise de similaridade do número de exemplares por local, segundo o coeficiente de BrayCurtis, com o programa PAST (HAMMER et al., 2003).

Para a análise dos itens alimentares identificados foram empregados os métodos de freqüência de ocorrência e de composição percentual, conforme HyNES (1950). O percentual da frequência de ocorrência foi calculado em função dos estômagos com conteúdo, através da fórmula: $\%$ fo $=(\mathrm{Ni} / \mathrm{N}) \times 100$; onde $\%$ fo $=$ freqüência de ocorrência de determinado item; $\mathrm{Ni}=$ número de estômagos com a presença do item $\mathrm{i} ; \mathrm{N}=$ número total de estômagos com conteúdos examinados.

A composição percentual foi calculada em função do número total de ocorrência dos itens, pela fórmula: \% $\mathrm{cp}=(\Sigma \mathrm{Ni} / \Sigma \mathrm{Nt}) \times 100 ;$ onde $\% \mathrm{cp}=$ composição percentual $=\Sigma$ da ocorrência de todos os itens $=100 \% ; \mathrm{Ni}=$ número de ocorrência do item i; $\mathrm{Nt}=$ total das ocorrências de todos os itens.
A composição percentual dos itens alimentares consumidos pelas quatro espécies foi ordenada pela Análise de Componentes Principais (ACP). Os percentuais quanto ao tipo (animal/vegetal) e à origem (autóctone/alóctone) foram comparados entre as espécies.

\section{RESULTADOS}

Das quatro espécies de Astyanax capturadas, apenas A. eigenmanniorum foi comum aos quatro trechos amostrados, com maior abundância no rio Iapó; $A$. scabripinnis esteve restrita ao rio Fortaleza, o de menor porte; A. altiparanae e A. fasciatus foram registradas nos rios Iapó e Tibagi, com maior abundância neste último (Tab. II).

Pela análise da constância foi constatada a preferência de A. altiparanae e A. fasciatus por rios de maior porte, uma vez que essas espécies foram constantes no rio Tibagi. Astyanax eigenmanniorum foi constante no rio Iapó e A. scabripinnis no rio Fortaleza (Tab. III). Pela comparação do número de exemplares com a sua ocorrência por trecho, foram encontrados baixos valores de similaridade, confirmando a preferência de cada espécie por ambientes específicos, pois cada uma delas foi registrada com abundância em apenas um dos rios (Fig. 3).

A composição dos recursos alimentares variou de 
Tabela II. Número de indivíduos de Astyanax capturados em cada um dos trechos amostrados no rio Tibagi e nos seus afluentes no período de maio de 2001 a abril de 2002.

\begin{tabular}{lrrcc}
\hline & \multicolumn{4}{c}{ Trechos amostrados } \\
\cline { 2 - 5 } Espécies & Fortaleza & Iapó & $\begin{array}{c}\text { Tibagi } \\
\text { acima }\end{array}$ & $\begin{array}{c}\text { Tibagi } \\
\text { abaixo }\end{array}$ \\
\hline A. altiparanae & 0 & 2 & 2 & 29 \\
A. eigenmanniorum & 4 & 102 & 21 & 0 \\
A. fasciatus & 0 & 27 & 84 & 76 \\
A. scabripinnis & 469 & 0 & 0 & 0 \\
\hline
\end{tabular}

11 a 23 categorias, sendo que $A$. scabripinnis utilizou o maior número de recursos e A. altiparanae, o menor (Tab. IV). Considerando os principais alimentos (mais de $70 \%$ do total da composição) para cada espécie, foram destacadas 11 categorias (em negrito na Tab. IV). As quatro espécies tiveram em comum três categorias: restos vegetais (folhas e sementes da vegetação terrestre), restos de insetos (de origem mista e não-identificados) e vegetação aquática.

Quanto aos itens principais ( $\mathrm{Cp}>10 \%)$, as quatro apresentaram dieta semelhante. Quanto aos secundários $(10 \%>\mathrm{Cp}>6 \%)$, a diferenciação na dieta é visível. Astyanax scabripinnis adicionou gramíneas, Trichoptera e Coleoptera em sua dieta. Astyanax eigenmanniorum teve dieta principalmente herbívora, adicionando restos vegetais e restos orgânicos. Os itens carvão e sedimento, embora não considerados
Tabela III. Constância de captura de quatro espécies de Astyanax em cada um dos trechos amostrados no rio Tibagi e nos seus afluentes no período de maio de 2001 a abril de 2002.

\begin{tabular}{lcccc}
\hline & \multicolumn{3}{c}{ Trechos amostrados } \\
\cline { 2 - 5 } \multicolumn{1}{c}{ Espécies } & Fortaleza & Iapó & $\begin{array}{c}\text { Tibagi } \\
\text { acima }\end{array}$ & $\begin{array}{c}\text { Tibagi } \\
\text { abaixo }\end{array}$ \\
\hline $\begin{array}{l}\text { A. altiparanae } \\
\text { A. eigenmanniorum } \\
\text { A. fasciatus }\end{array}$ & Acidental & Acidental & Acessória & Constante \\
A. scabripinnis & Constante & Acessória & \\
\hline
\end{tabular}

alimentos, foram ingeridos por A. eigenmanniorum em quantidades semelhantes aos itens secundários. Astyanax fasciatus e A. altiparanae tiveram dieta principalmente herbívora, a primeira espécie adicionando, ainda, insetos terrestres e peixes entre os alimentos secundários (Fig. 4).

Quando comparadas as proporções animal/ vegetal (Fig. 5), A. altiparanae e A. scabripinnis consumiram vegetais em maior proporção; as outras duas espécies consumiram essas duas categorias em proporção semelhante, sendo a categoria animal um pouco mais consumida. A proporção quanto à origem autóctone/alóctone (Fig. 6), para A. altiparanae e A. scabripinnis, foi maior para os alimentos alóctones, representados principalmente pelos itens restos vegetais e sementes, os principais responsáveis por essa diferença.

Tabela IV. Número de ocorrência (N), frequiência de ocorrência (fo) e composição percentual (cp) dos alimentos utilizados por quatro espécies de Astyanax na bacia do rio Tibagi (quatro trechos amostrados entre maio de 2001 e abril de 2002). Em negrito, os alimentos principais. As linhas destacadas referem-se aos itens alóctones; os itens R (restos de insetos) e V (detrito) foram considerados de origem mista. (*, Nematoda, Nematomorpha, Crustacea, Arachnida.)

\begin{tabular}{|c|c|c|c|c|c|c|c|c|c|c|c|c|}
\hline \multirow[b]{3}{*}{ Alimentos } & \multicolumn{12}{|c|}{ Espécies } \\
\hline & \multicolumn{3}{|c|}{ A. scabripinnis } & \multicolumn{3}{|c|}{ A. eigenmanniorum } & \multicolumn{3}{|c|}{ A. fasciatus } & \multicolumn{3}{|c|}{ A. altiparanae } \\
\hline & $\mathrm{N}$ & $\%$ fo & $\% \mathrm{cp}$ & $\mathrm{N}$ & $\%$ fo & $\% \mathrm{cp}$ & $\mathrm{N}$ & $\%$ fo & $\% \mathrm{cp}$ & $\mathrm{N}$ & $\%$ fo & $\%$ сp \\
\hline \multicolumn{13}{|l|}{ I. VEGETAIS } \\
\hline A. Algas & 69 & 21 & 5,9 & 16 & 17,8 & 4,5 & 2 & 2,2 & 0,8 & & & \\
\hline B. Plantas aquáticas (macrófitas) & 164 & 49,8 & 14,1 & 81 & 90 & 22,7 & 58 & 64,4 & 22,8 & 7 & 31,8 & 11,5 \\
\hline C. Restos de vegetais superiores & 198 & 60,2 & 17 & 28 & 31,1 & 7,8 & 24 & 26,7 & 9,4 & 6 & 27,3 & 9,8 \\
\hline D. Gramíneas & 78 & 23,7 & 6,7 & 1 & 1,1 & 0,3 & 3 & 3,3 & 1,2 & 3 & 13,6 & 4,9 \\
\hline E. Sementes & 68 & 20,7 & 5,8 & 10 & 11,1 & 2,8 & 23 & 25,6 & 9,1 & 16 & 72,7 & 26,2 \\
\hline \multicolumn{13}{|l|}{ II. INSETOS } \\
\hline F. Coleoptera (imaturos) & 1 & 0,3 & 0,1 & & & & & & & & & \\
\hline G. Coleoptera (adultos) & 83 & 25,2 & 7,1 & 16 & 17,8 & 4,5 & 6 & 6,7 & 2,4 & 1 & 4,5 & 1,6 \\
\hline H. Ephemeroptera (imaturos) & 11 & 3,3 & 0,9 & 2 & 2,2 & 0,6 & 3 & 3,3 & 1,2 & & & \\
\hline I. Hemiptera & 9 & 2,7 & 0,8 & & & & 1 & 1,1 & 0,4 & & & \\
\hline J. Diptera (imaturos e adultos) & 5 & 1,5 & 0,4 & & & & 1 & 1,1 & 0,4 & & & \\
\hline K. Ceratopogonidae (imaturos) & 4 & 1,2 & 0,3 & 4 & 4,4 & 1,1 & & & & & & \\
\hline L. Trichoptera (imaturos) & 76 & 23,1 & 6,5 & 17 & 18,9 & 4,8 & 4 & 4,4 & 1,6 & & & \\
\hline M. Simuliidae (imaturos) & 11 & 3,3 & 0,9 & & & & 1 & 1,1 & 0,4 & & & \\
\hline N. Chironomidae (imaturos) & 8 & 2,4 & 0,7 & & & & & & & & & \\
\hline O. Odonata (náiade) & 35 & 10,6 & 3 & 3 & 3,3 & 0,8 & 2 & 2,2 & 0,8 & 1 & 4,5 & 1,6 \\
\hline P. Hymenoptera & 15 & 4,6 & 1,3 & 21 & 23,3 & 5,9 & 18 & 20 & 7,1 & 1 & 4,5 & 1,6 \\
\hline Q. Lepidoptera (imaturos) & 11 & 3,3 & 0,9 & 7 & 7,8 & 2 & & & & & & \\
\hline $\begin{array}{l}\text { R. Restos de insetos } \\
\text { III. PEIXES }\end{array}$ & 195 & 59,3 & 16,8 & 62 & 68,9 & 17,4 & 60 & 66,7 & 23,6 & 15 & 68,2 & 24,6 \\
\hline $\begin{array}{l}\text { S. Escamas, Ovócitos e Restos } \\
\text { IV. OUTROS ANIMAIS }\end{array}$ & 26 & 7,9 & 2,2 & 16 & 17,8 & 4,5 & 17 & 18,9 & 6,7 & 9 & 40,9 & 14,8 \\
\hline $\begin{array}{l}\text { T. Diversos* } \\
\text { V. DIVERSOS }\end{array}$ & 13 & 4 & 1,1 & 2 & 2,2 & 0,6 & & & & & & \\
\hline U. Carvão, Restos Orgânicos & 13 & 4 & 1,1 & 32 & 35,6 & 9 & 12 & 13,3 & 4,7 & 1 & 4,5 & 1,6 \\
\hline V. Detrito & 39 & 11,9 & 3,4 & 13 & 14,4 & 3,6 & 7 & 7,8 & 2,8 & & & \\
\hline X. Sedimento (areia e terra) & 32 & 9,7 & 2,7 & 26 & 28,9 & 7,3 & 12 & 13,3 & 4,7 & 1 & 4,5 & 1,6 \\
\hline Total de estômagos analisados & 329 & & & 90 & & & 90 & & & 22 & & \\
\hline Total de ocorrência dos itens & & & 1164 & & & 357 & & & 254 & & & 61 \\
\hline
\end{tabular}




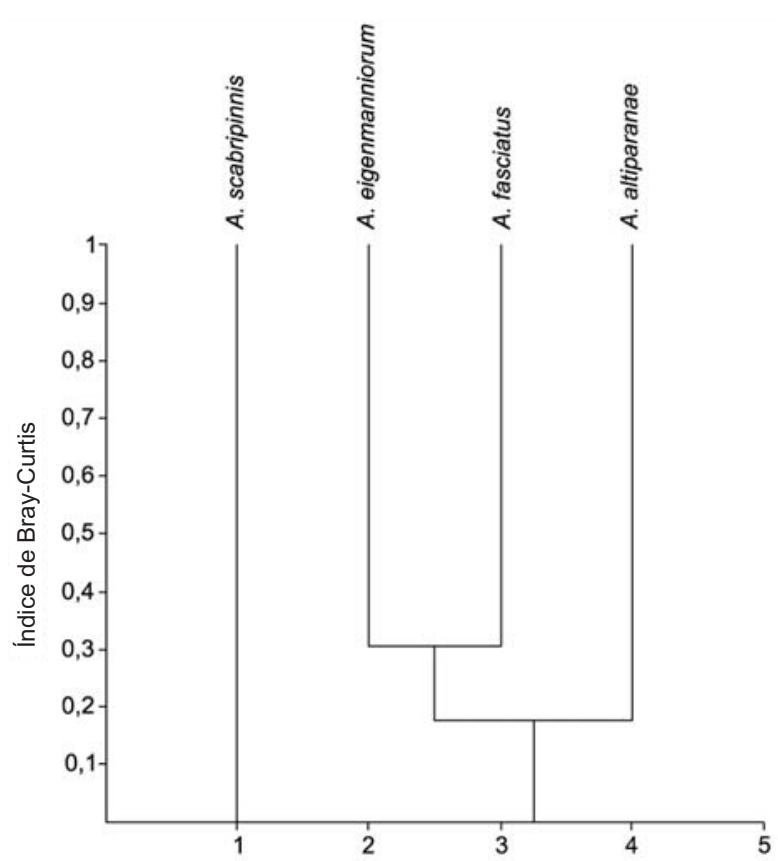

Fig. 3. Dendrograma de similaridade na distribuição espacial de quatro espécies de Astyanax na bacia do rio Tibagi (quatro trechos amostrados entre maio de 2001 e abril de 2002).
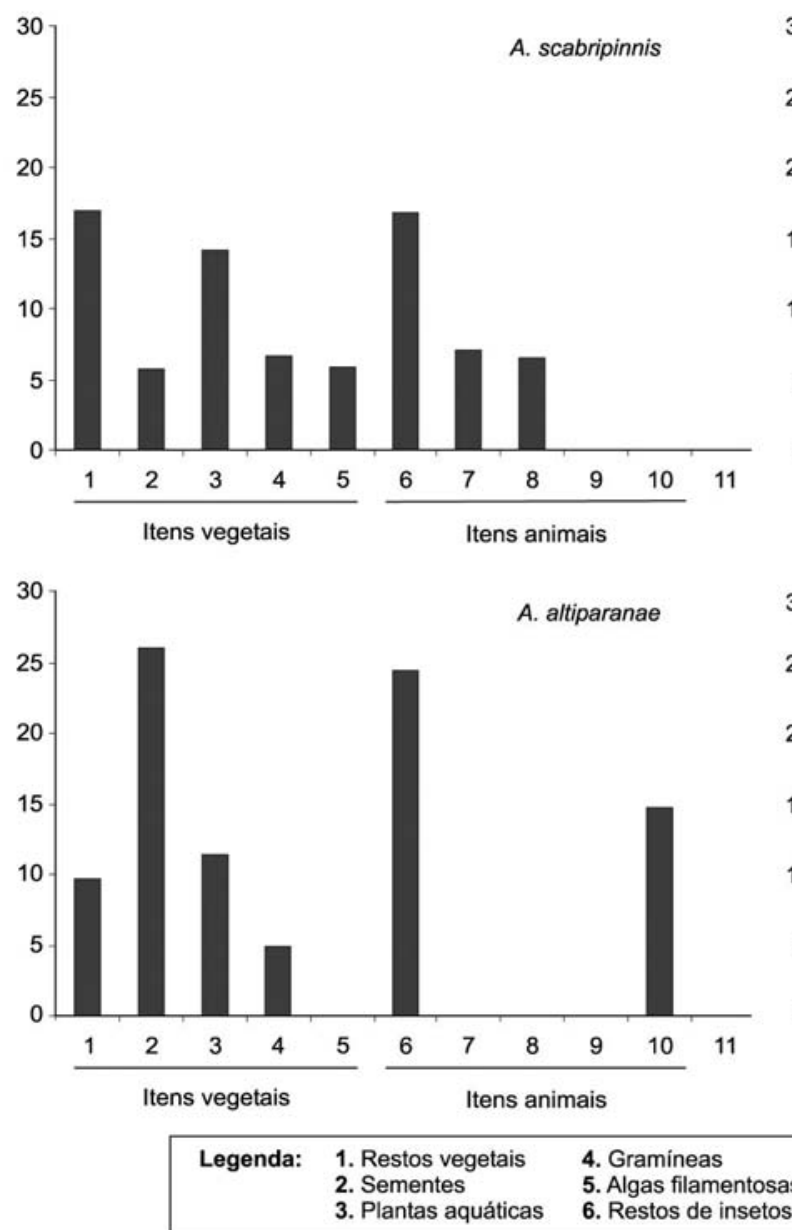

A Análise de Componentes Principais (ACP) ordenou os percentuais da composição dos recursos utilizados pelas espécies. A variância total dos dados foi explicada, pelos dois primeiros eixos, em $85,67 \%$. O eixo 1 da componente (com 49,36\%) destacou a importância do item plantas aquáticas (item B), consumidas principalmente por A. fasciatus e A. eigenmanniorum. $\mathrm{O}$ eixo 2 (com 13,31\%) destacou os alimentos diferenciais ou principais para A. altiparanae (itens $\mathrm{E}, \mathrm{R}$ e $\mathrm{S}$ ) e $A$. scabripinnis, espécie que utilizou maior diversidade de itens (Fig. 7; ver Tab. IV para conferir itens).

\section{DISCUSSÃO}

Astyanax scabripinnis só foi capturada no rio Fortaleza, indicando preferência por rios de menor porte. Shibatta et al. (2002) também registraram essa espécie entre as poucas que foram exclusivas em riachos das regiões média e baixa da bacia do rio Tibagi. As outras três espécies foram registradas por esses autores no rio Tibagi, em seus afluentes e subafluentes, tal como verificado neste estudo.

No rio Tibagi, aqui o de maior porte, BENNEMANN $e t$ al. (1995) encontraram A. altiparanae e $A$. eigenmanniorum, a primeira nos cinco trechos que estudaram e a segunda em apenas dois, tendo mostrado
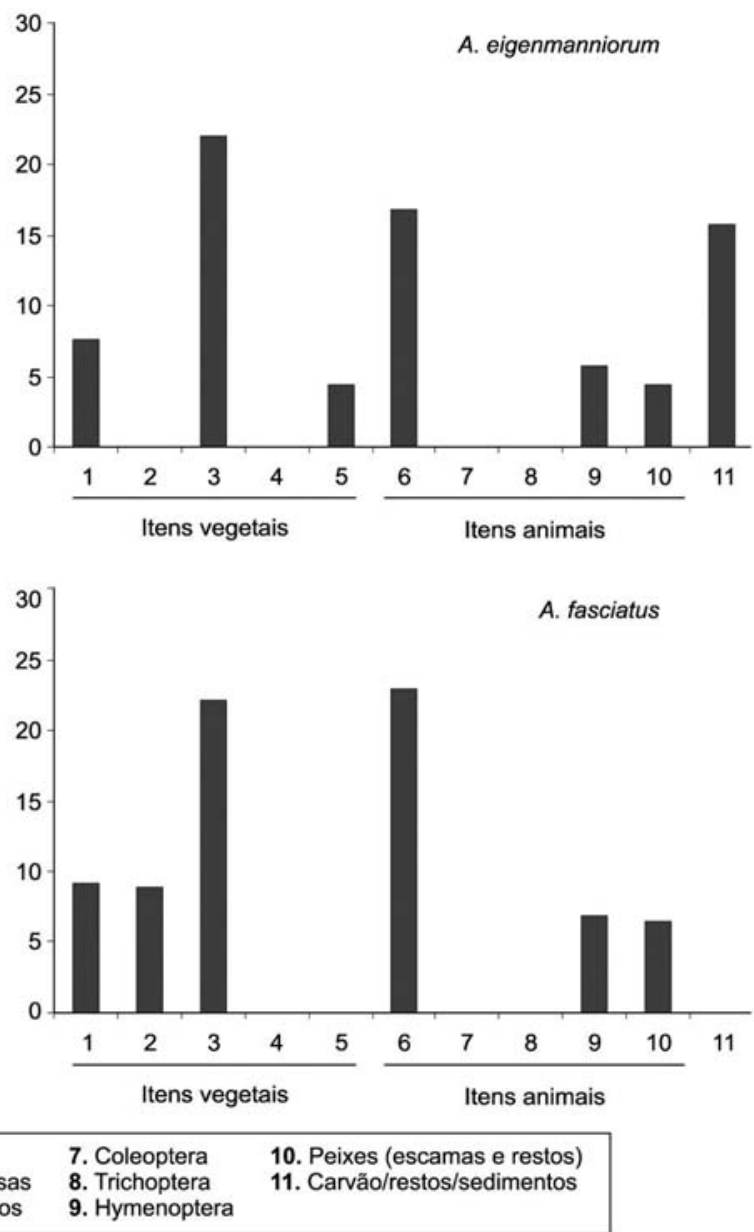

Fig. 4. Percentuais de ocorrência dos principais recursos alimentares consumidos por quatro espécies de Astyanax na bacia do rio Tibagi (quatro trechos amostrados entre maio de 2001 e abril de 2002). 


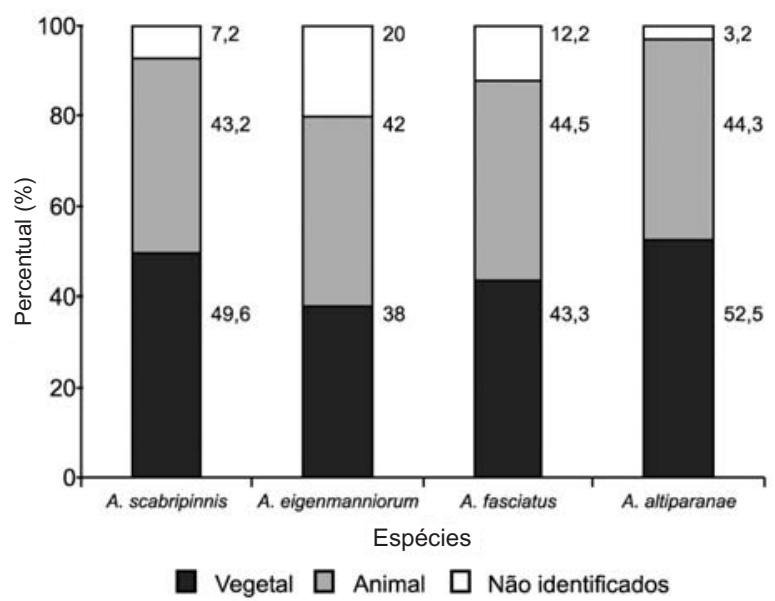

Fig. 5. Composição percentual dos alimentos utilizados por quatro espécies de Astyanax na bacia do rio Tibagi quanto ao tipo animal ou vegetal (quatro trechos amostrados entre maio de 2001 e abril de 2002).

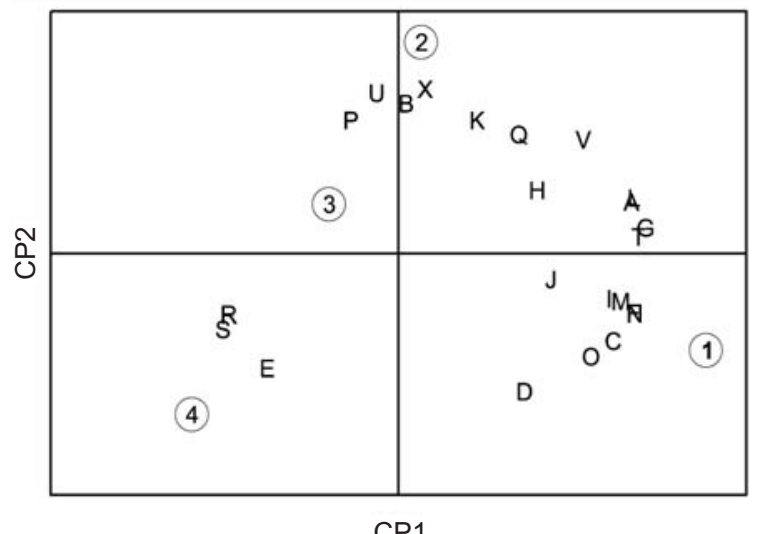

\begin{tabular}{|llll|}
\hline Legenda: & Astyanax scabripinnis & (3) & Astyanax fasciatus \\
& (2) Astyanax eigenmanniorum & (4) & Astyanax altiparanae \\
\hline
\end{tabular}

Fig. 7. Ordenação da composição percentual dos itens alimentares consumidos por quatro espécies de Astyanax na bacia do rio Tibagi pela Análise de Componentes Principais (ACP) (quatro trechos amostrados entre maio de 2001 e abril de 2002). As letras correspondem aos itens alimentares que estão listados na Tab. IV.

preferência por ribeirões próximos à foz de grandes rios. Conforme relatado pelos autores, A. eigenmanniorum foi capturada na foz dos ribeirões Lambari e Três Bocas, afluentes do rio Tibagi nas regiões média e baixa da bacia, respectivamente.

CASTRO et al. (2003) realizaram um amplo estudo sobre as espécies de peixes presentes em 17 riachos de pequena ordem, afluentes do rio Paranapanema, não registrando A. eigenmanniorum; as outras três espécies foram freqüentemente encontradas. Em trechos de um afluente do rio Mogi-Guaçu, Oliveira \& Garavello (2003) registraram aquelas três espécies, mas também não encontraram A. eigenmanniorum. Seus resultados reforçam a nossa hipótese de que essa espécie explora rios de maior porte em trechos próximos à confluência de afluentes.

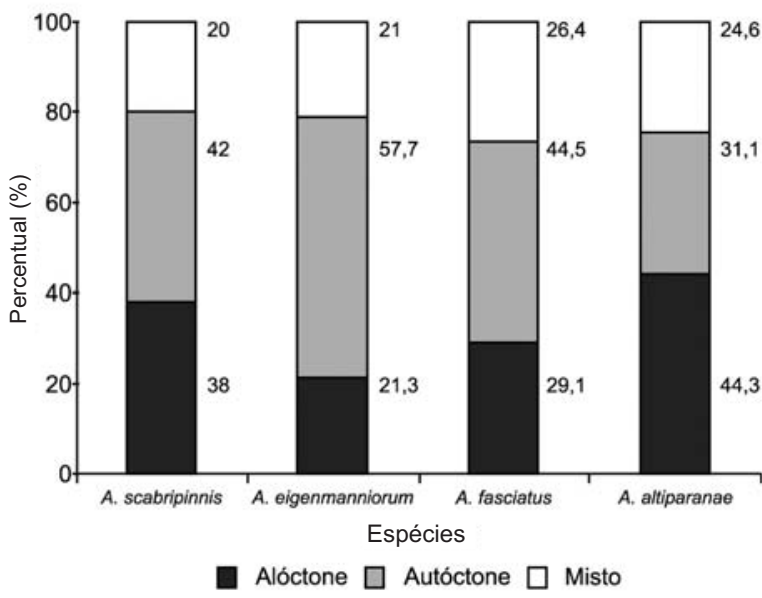

Fig. 6. Composição percentual dos alimentos utilizados por quatro espécies de Astyanax na bacia do rio Tibagi quanto à origem autóctone ou alóctone (quatro trechos amostrados entre maio de 2001 e abril de 2002)

Outro resultado que pode amparar esta hipótese é o obtido por GARCIA \& VIEIRA (2001), que registraram $A$. eigenmanniorum como dominante na foz de riachos próximos ao ambiente estuarino da região costeira da lagoa dos Patos, tendo sido encontrada entre as espécies que invadiram o estuário e foram abundantes na época de influência do fenômeno El Niño em 1997-1998, quando houve excesso de chuva e o nível de água doce aumentou.

Astyanax fasciatus e A. altiparanae estão amplamente distribuídas em diferentes ambientes da bacia do rio Paraná. No entanto, para essas duas espécies, pode ser observada preferência por determinados hábitats. LEMES \& GARUTTI (2002) registraram A. altiparanae como espécie acessória em hábitats poções e rápidos e $A$. fasciatus como espécie acidental em hábitats rápidos. Abes \& Agostinho (2001) as encontraram em um pequeno riacho: a primeira foi constante nos três trechos (superior, médio e inferior) que os autores analisaram e a segunda foi encontrada apenas no trecho médio, com $50 \%$ de constância nas capturas. ORSI et al. (2004) verificaram a presença de A. altiparanae, principalmente em trechos pouco caudalosos, na região baixa da bacia do rio Tibagi. Em reservatórios, entre as espécies de Astyanax, essas duas são as mais comumente encontradas (ARCIFA et al., 1991; Dias \& GaraVello, 1998; Hahn et al., 1998).

Através da baixa similaridade entre o número de exemplares capturados por trecho, a dominância em número de indivíduos e a constância de apenas uma espécie em cada um dos rios ou trechos, evidencia-se que a ocupação de rios de diferentes portes é um dos aspectos diferenciais que segregam essas espécies na bacia do Tibagi. Astyanax scabripinnis esteve restrita ao rio de menor porte, A. eigenmanniorum teve ocorrência em rios maiores, preferencialmente na foz, e A. altiparanae e A. fasciatus apresentaram distribuição mais ampla, apesar de mais abundantes apenas em um dos trechos do rio Tibagi, a primeira, no trecho Tibagi abaixo, a segunda, no trecho Tibagi acima.

Embora essas espécies ocupem os mais diferentes tipos e tamanhos de ambientes (riachos, lagoas, reservatórios e rios), seu hábitat preferencial é a área 
litorânea, onde encontram abrigo e alimento. Esses aspectos são amplamente relatados na literatura sobre as espécies pertencentes ao gênero, sendo que a base dos alimentos consumidos é constituída principalmente de insetos e vegetais superiores de origem alóctone.

As mudanças na utilização desses recursos estão relacionadas às características do ambiente e às alterações que este sofre. Segundo BARRELla et al. (2000), em rios de menor porte ou de menor volume de água é comum que os peixes utilizem maior quantidade de recursos alimentares de origem alóctone.

Nos rios de diferentes portes estudados nesta pesquisa, as quatro espécies de Astyanax tiveram semelhança nos recursos alimentares utilizados, relacionados à diversidade de alimentos (animal/vegetal) e à origem (alóctone/autóctone). $\mathrm{O}$ fato de A. scabripinnis ter sido uma das espécies que consumiram maior quantidade de recursos alóctones pode ter relação com o porte do rio no qual foi encontrada, como destacam BARRElla et al. (2000). CASATTI (2002) encontrou maior quantidade de insetos alóctones para $A$. altiparanae de um pequeno riacho da bacia do alto Paraná.

Astyanax altiparanae, que neste estudo foi encontrada no rio de maior porte, foi a espécie que teve o menor número de exemplares capturados entre as quatro espécies. Em rios maiores, quando a área marginal é alterada, as espécies de Astyanax podem ter seu número bastante reduzido ou mesmo desaparecer. Essa situação foi observada por BENNEMANN \& SHIBATTA (2002) em uma área litorânea do rio Tibagi, estudada por eles durante cinco períodos; num período em que houve seca e o rio se restringiu à calha principal, $A$. altiparanae desapareceu.

Neste trabalho, independentemente das diferenças quanto à origem, os recursos utilizados pelas espécies de Astyanax foram principalmente insetos e vegetais, como também registrado por EsTEVES \& GALETTI (1995), para três espécies em uma lagoa do rio Mogi-Guaçu; por HAHN et al. (1998), para quatro espécies no reservatório Itaipu; por LOBÓN-CERVIÁ \& BENNEMANN (2000), para uma espécie no rio Tibagi; por ANDRIAN et al. (2001), para uma espécie num reservatório no rio Corumbá; por CASSEMIRO et al. (2002), para A. altiparanae em um reservatório no rio Iguaçu; por VILELLA et al. (2002), para seis espécies em diferentes trechos do rio Maquiné (RS); e por CASATTI et al. (2003), no reservatório de Rosana, no rio Paranapanema, para uma espécie.

O hábito alimentar generalista das quatro espécies de Astyanax analisadas neste trabalho ficou bem caracterizado pelos resultados obtidos, sendo coerente com o que consta na literatura, mesmo considerando diferentes ambientes. Nos três rios aqui estudados, essas espécies utilizam predominantemente um tipo de hábitat, a área marginal, aproveitando não apenas o abrigo, mas também os recursos alimentares que estão ali disponíveis.

Astyanax eigenmanniorum se distinguiu das demais espécies por se aproveitar de plantas aquáticas, que estavam em grande disponibilidade, aderidas às margens rochosas. Embora os quatro trechos se caracterizem por apresentar, no fundo do rio e nas margens, porções rochosas com grande quantidade de vegetação aquática aderida, essa espécie foi abundante e constante apenas no rio Iapó. Resultados similares foram encontrados por VILELLA et al. (2002) no rio Maquiné, no qual A. eigenmanniorum foi abundante apenas na região baixa, onde o fundo era rochoso e havia maior profundidade e disponibilidade de macrófitas. Os autores destacam que, entre as seis espécies de Astyanax analisadas, o item areia foi ingerido em quantidade semelhante aos alimentos principais apenas por A. eigenmanniorum, e sugerem que sua ingestão deva ter um papel importante para auxiliar na fragmentação das plantas consumidas, tal como observado nesta pesquisa.

Agradecimentos. Ao Departamento de Biologia Geral da Universidade Estadual de Ponta Grossa; à Fundação Araucária e ao CNPq, pelo apoio financeiro; ao Dr. Oscar Akio Shibatta pela identificação dos peixes; ao Dr. Reinaldo José de Castro pelo auxílio na análise estatística; ao Dr. Hernán Fandino pela correção do abstract; às estagiárias Cibele Maria Vianna Zanon e Karen Vangela de Geus, pelo auxílio em campo e nos trabalhos de laboratório; a Artur Ricardo Nolti, pela ajuda na realização das coletas; a Francisco Vangela de Geus, proprietário da fazenda Santo Amaro, onde foi amostrado o rio Fortaleza.

\section{REFERÊNCIASBIBLIOGRÁFICAS}

Abes, S. S. \& Agostinho, A. A. 2001. Spatial patterns in fish distributions and structure of the ichthyocenosis in the Água Naci stream, upper Paraná river basin, Brazil. Hydrobiologia 445: 217-227.

Andrian, I. F.; Silva, H. B. R. \& Peretti, D. 2001. Dieta de Astyanax bimaculatus (Linnaeus, 1758) (Characiformes, Characidae), da área de influência do reservatório de Corumbá, estado de Goiás, Brasil. Acta Scientiarum 23(2): 435-440.

Arcifa M. S.; Northcote, T. G. \& Froenlich, O. 1991. Interactive ecology of two cohabiting characin (Astyanax fasciatus and Astyanax bimaculatus) in an eutrophic brasilian reservoir. Journal of Tropical Ecology 7:257-268.

Barrella, W.; Petrere, M.; Smith, W. S. \& Montag, L. F. A. 2000. As relações entre as matas ciliares, os rios e os peixes. In: Rodrigues, R. R. \& Leitão, H. F. eds. Matas ciliares: conservação e recuperação. São Paulo, Edusp. p.187-207.

Bennemann, S. T. \& Shibatta, O. A. 2002. Dinâmica de uma assembléia de peixes do rio Tibagi. In: Medri, M. E.; BIANCHINI, E; Shibatta, O. A. \& Pimenta, J. A. eds. A bacia do rio Tibagi. Londrina, Universidade Estadual de Londrina. p.433-442.

Bennemann, S. T.; Shibatta, O. A. \& Garavello, J. C. 2000. Peixes do rio Tibagi: uma abordagem ecológica. Londrina, Eduel. 62p.

Bennemann, S. T.; Silva-Souza, A. T. \& Rodrigues, G. A. R. 1995. Composición ictiofaunistica en cinco localidades de la cuenca del rio Tibagi, PR - Brasil. Interciencia 20(1):7-13.

Casatti, L. 2002. Alimentação dos peixes em um riacho do Parque Estadual Morro do Diabo, bacia do alto rio Paraná, sudeste do Brasil. Biota Neotropica 2(2):1-14.

Casatti, L.; Mendes, H. F. \& Ferreira, K. M. 2003. Aquatic macrophytes as feeding site for small fishes in the Rosana reservoir, Paranapanema river, Southeastern Brazil. Brazilian Journal of Biology 63(2):213-222.

Cassemiro, A. S.; Hahn, N. S. \& Fugi, R. 2002. Avaliação da dieta de Astyanax altiparanae Garutti \& Britski, 2000 (Ostheichthyes, Tetragonopterinae) antes e após a formação do reservatório de Salto Caxias, estado do Paraná, Brasil. Acta Scientiarum 24(2):419-425.

Castro, R. M. C.; Casatti, L.; Santos, H. F.; Ferreira, K. M.; Ribeiro, A. C.; Benine, R. C.; Dardis, G. Z. P.; Melo, A. L. A.; Stoppiglia, R.; Abreu, T. X.; Bockmann, F. A.; Carvalho, M.; Gibran, F. Z. \& Lima, F. C. T. 2003. Estrutura e composição da ictiofauna de riachos do rio Paranapanema, sudeste e sul do Brasil. Biota Neotropica 3(1):1-31.

Dias, J. H. \& Garavello, J. C. 1998. Ecological studies on the fish 
community of Salto Grande reservoir, Paranapanema river basin, São Paulo, Brazil. Verhein International Verein Limnologie 26:2228-2231.

Esteves, K. E. \& Galetti, P. M. 1995. Food partitioning among characids of a small brazilian floodplain lake from the Paraná river basin. Enviromental Biology of Fishes 42:375-389.

Garcia, A. M. \& Vieira, J. P. 2001. O aumento da diversidade de peixes no estuário da lagoa dos Patos durante o episódio El Niño 1997-1998. Atlântica 23:133-152.

Hahn, N. S.; Agostinho, A. A.; Gomes, L. C. \& Bini, L. M. 1998. Estrutura trófica da ictiofauna do reservatório de Itaipu (Paraná-Brasil) nos primeiros anos de formação. Interciência 23(5): 299-305.

Hammer, O.; Harper, D. A. \& Ryan, P. D. 2003. PAST Paleontolological Statistics ver. 1.12. Disponível em: <http://www.folk.uio.no/ohammer/past>. Acesso em: 31/07/ 2003.

HynEs, H. B. N. 1950. The food of fresh-water sticklebacks (Gasterosteus aculeatus and Pygosteus pungitius), with a review of methods used in studies of the food of fishes. Journal of Animal Ecology 19:36-57.

Lemes, E. M. \& Garutti, V. 2002. Ecologia da ictiofauna de um córrego de cabeceira da bacia do alto rio Paraná, Brasil. Iheringia, Série Zoologia 92(3):69-78.

Lobón-Cerviá, J. \& Bennemann, S. T. 2000. Temporal trophic shifts and feeding diversity in two sympatric, neotropical, omnivorous fishes: Astyanax bimaculatus and Pimelodus maculatus in rio Tibagi (Paraná, Southern Brazil). Archiv für Hydrobiology 149(2):285-306.

MAACK, R. 1968. Geografia física do estado do Paraná. Rio de Janeiro, J. Olympio. 442p.

Oliveira, A. K. \& Garavello, J. C. 2003. Fish assemblage composition in a tributary of the Mogi Guaçu river basin, southeastern Brazil. Iheringia, Série Zoologia 93(2):127-138

Orsi, M. L.; Shibatta, O. A. \& Silva-Souza, A. T. 2002. Caracterização biológica de populações de peixes do rio Tibagi, localidade de Sertanópolis. In: Medri, M. E.; Bianchini, E. Shibatta, O. A. \& Pimenta, J. A. eds. A bacia do rio Tibagi. Londrina, Universidade Estadual de Londrina. p.425-432.

Orsi, M. L.; Carvalho, E. D. \& Foresti, F. 2004. Biologia populacional de Astyanax altiparanae Garutti \& Britski 2000 (Teleostei, Characidae) do médio rio Paranapanema, Paraná, Brasil. Revista Brasileira de Zoologia 21(2):207-218.

Shibatta, O. A.; Orsi, M. L.; Bennemann, S. T. \& Silva-Souza, A. T. 2002. Diversidade e distribuição de peixes na bacia do rio Tibagi. In: Medri, M. E.; Bianchini, E.; Shibatta, O. A. \& Pimenta, J. A. eds. A bacia do rio Tibagi. Londrina, Universidade Estadual de Londrina. p.403-423.

Veregue, A. M. L. \& Orsi, M. L. 2003. Biologia reprodutiva de Astyanax scabripinnis paranae (Eigenmann) (Osteichthyes, Characidae), do ribeirão das Marrecas, bacia do rio Tibagi, Paraná. Revista Brasileira de Zoologia 20(1):97-105.

Vilella, F. S.; Becker, F. G. \& Hartz, S. M. 2002. Diet of Astyanax species (Teleostei, Characidae) in an Atlantic forest river in Southern Brazil. Brazilian Archives of Biology and Technology 45(2):223-232. 